\title{
Site Scientific Mission Plan for the Southern Great Plains CART Site January-June 2000
}

Prepared for the U.S. Department of Energy under Contract W-31-109-Eng-38

Site Program Manager Office Environmental Research Division Argonne National Laboratory Argonne, IL 60439 


\section{DISCLAIMER}

This report was prepared as an account of work sponsored by an agency of the United States Government. Neither the United States Government nor an agency thereof, nor any of their employees, makes any warranty, express or implied, or assumes any legal liability or responsibility for the accuracy, completeness, or usefulness of any information, apparatus, product, or process disclosed, or represents that its use would not infringe privately owned rights. Reference herein to any specific commercial product, process, or service by trade name, trademark, manufacturer, or otherwise, does not necessarily constitute or imply its endorsement, recommendation, or favoring by the United States Government or any agency

thereof. The views and opinions of authors expressed herein do not necessarily state or reflect those of the United States Government or any agency thereof.

Publishing support services were provided by Argonne's Information and Publishing Division. (For more information, see IPD's home page: http://www.ipd.anl.gov.)

Available electronically at these sites:

-http://www.arm.gov/docs/sites/sgp/internal/ ssmp14.pdf

•http://www.doe.gov/bridge 
ARM-00-006

\section{Site Scientific Mission Plan for the Southern Great Plains CART Site \\ January-June 2000}

January 2000

Randy A. Peppler, ${ }^{1}$ Douglas L. Sisterson, ${ }^{2}$ and Peter Lamb ${ }^{1}$

${ }^{1}$ Cooperative Institute for Mesoscale Meteorological Studies, The University of Oklahoma, Norman, OK 73019

${ }^{2}$ Environmental Research Division, Argonne National Laboratory, Argonne, IL 60439

Work supported by United States Department of Energy, Office of Science, Office of Biological and Environmental Research, Environmental Sciences Division 


\section{CONTENTS}

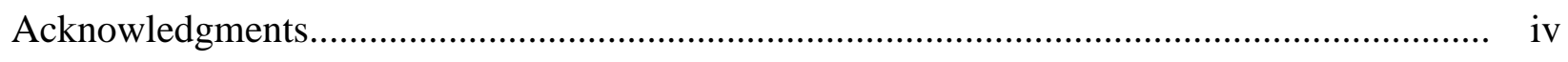

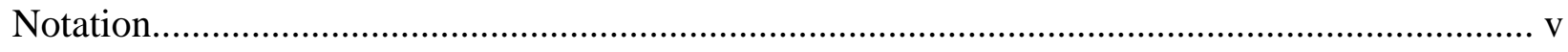

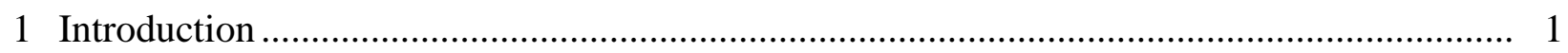

2 Summary of Scientific Goals and Site Priorities......................................................... 2

2.1 Programmatic Goals.................................................................................. 2

2.2 Priorities for Site Activities during This Period — Executive Summary ........................ 3

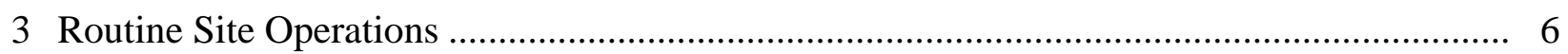

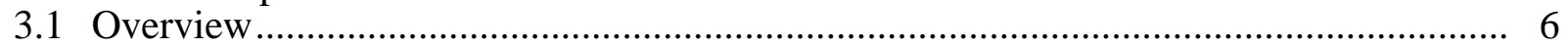

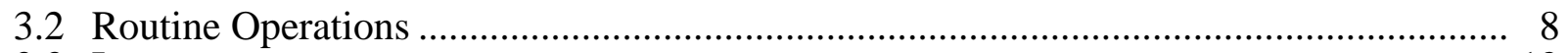

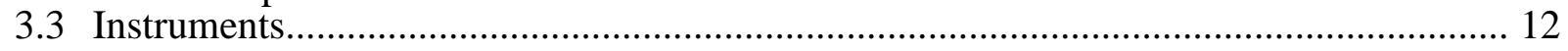

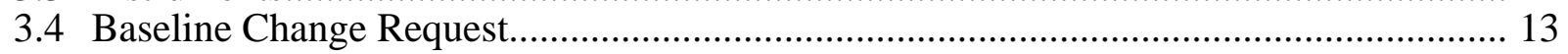

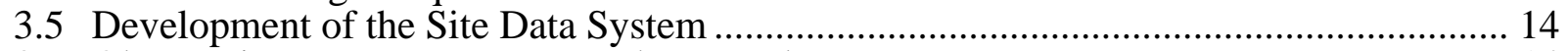

3.6 Observations, Measurements, and External Data ............................................... 14

3.7 Site Development Activities during This Period .............................................. 14

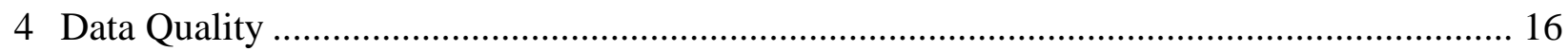

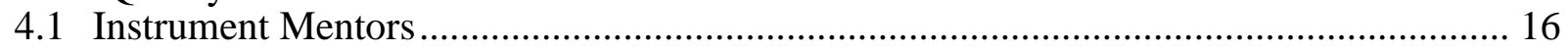

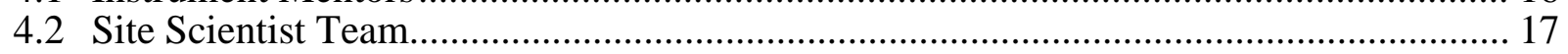

4.3 Value-Added Products and Quality Measurement Experiments ................................... 18

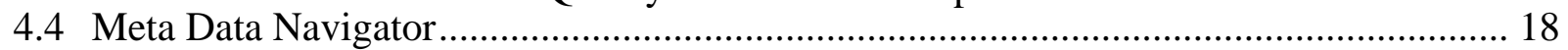

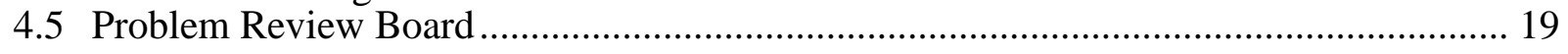

5 Scientific Investigations and Opportunities ............................................................... 20

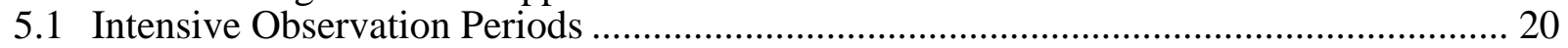

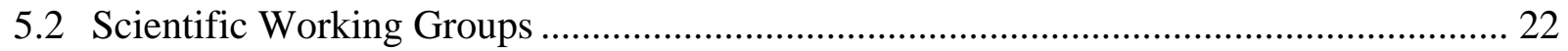

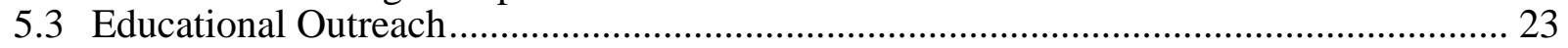

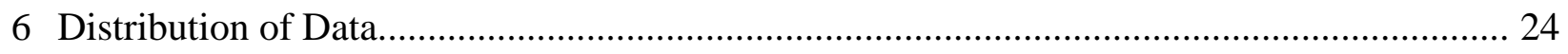

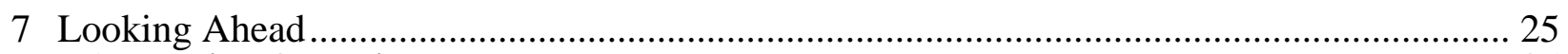

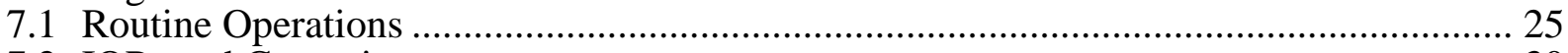

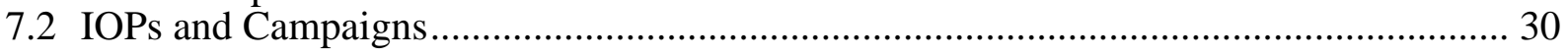

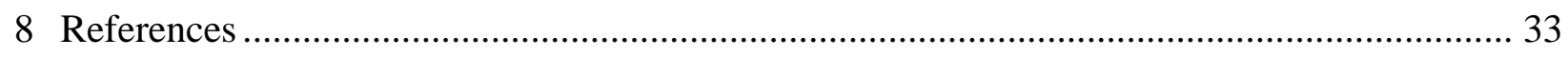

\section{FIGURE}

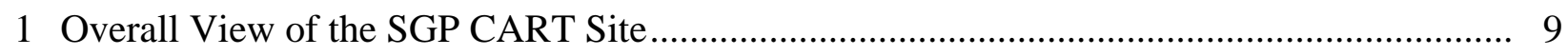

\section{TABLE}

1 Instruments and Observational Systems Anticipated at the Central, Boundary, Extended, and Auxiliary Facilities on June 30, 2000. 


\section{ACKNOWLEDGMENTS}

The research reported here was supported by the Atmospheric Radiation Measurement Program of the Environmental Sciences Division, Office of Biological and Environmental Research, Office of Science, U.S. Department of Energy, under contract PNL 144880-A-Q1 at the Cooperative Institute for Mesoscale Meteorological Studies, University of Oklahoma (Peppler and Lamb), and under contract W-31-109-Eng-38 at Argonne National Laboratory (Sisterson). 


\section{NOTATION}

3-D

AERI

AFWEX

AOS

AOSAIR

ARESE

ARM

AVHRR

BBSS

BCR

BLC

BORCAL

BSRN

CAR

CART

CDT

CQI

CSPHOT

CST

DIAL

DOE

DQR

DSIT

EBBR

ECOR

EOS

ETL

FIRE

FTP

GCM

GIF

GPS

GRAMS

GST

IDP

IDPC

IHOP

IMF

IOP

IRF

IRT

ISLSCP

IT

MCS three-dimensional

atmospherically emitted radiance interferometer

ARM-FIRE Water Vapor Experiment

aerosol observation system

aerosol observation system by aircraft

ARM Enhanced Shortwave Experiment

Atmospheric Radiation Measurement (Program)

advanced very-high-resolution radiometer

balloon-borne sounding system

baseline change request

Belfort laser ceilometer

Broadband Outdoor Radiometer CALibration

Baseline Surface Radiation Network

Corrective Action Report

Cloud and Radiation Testbed

central daylight time

Continuous Quality Improvement (Program)

Cimel sunphotometer

central standard time

differential-absorption lidar

U.S. Department of Energy

Data Quality Report

Data and Science Integration Team

energy balance Bowen ratio

eddy correlation

Earth Observing System

Environmental Technology Laboratory

First ISLSCP Regional Experiment

file transfer protocol

general circulation model

guest instrument facility

global positioning system

ground-based radiometer autonomous measurement system

GPS Science and Technology

Instrument Development Program

integrated data processing circuit

International $\mathrm{H}_{2} \mathrm{O}$ Project

instrument maintenance facility

intensive observation period

instantaneous radiative flux

infrared thermometer

International Satellite Land-Surface Climatology Project

Instrument Team

Mesoscale Convective Systems 


\section{NOTATION (Cont.)}

\begin{tabular}{|c|c|}
\hline MDN & Meta Data Navigator \\
\hline MDS & Meta Data System \\
\hline MFR & multifilter radiometer \\
\hline MFRSR & multifilter rotating shadowband radiometer \\
\hline MMCR & millimeter cloud radar \\
\hline MOPA & Master Oscillator Power Amplifier \\
\hline MOPITT & Measurements of Pollution in the Troposphere \\
\hline MOVE & MOPITT Validation Exercise \\
\hline MPL-HR & micropulse lidar-high resolution \\
\hline MWR & microwave radiometer \\
\hline NASA & National Aeronautics and Space Administration \\
\hline NDVI & non-dimensional vegetative index \\
\hline NFOV & narrow-field-of-view zenith-pointing filtered radiometer \\
\hline NIMFR & normal-incidence multifilter radiometer \\
\hline NIP & normal-incidence pyrheliometer \\
\hline NOAA & National Oceanic and Atmospheric Administration \\
\hline OMIS & Operations Management Information System \\
\hline PI & principal investigator \\
\hline PIF & Problem Identification Form \\
\hline PMEL & Pacific Marine Environmental Laboratory \\
\hline PRB & Problem Review Board \\
\hline PSAP & particle soot absorption photometer \\
\hline PSP & precision spectral pyranometer \\
\hline QME & quality measurement experiment \\
\hline RASS & radio acoustic sounding system \\
\hline $\mathrm{RCF}$ & radiometer calibration facility \\
\hline RSS & rotating shadowband spectrometer \\
\hline RWP & radar wind profiler \\
\hline SBIR & Small Business Innovative Research (Program) \\
\hline $\mathrm{SCM}$ & single-column model \\
\hline SDS & site data system \\
\hline SGP & Southern Great Plains \\
\hline SI & International System of Units \\
\hline SIROS & solar and infrared radiation observing system \\
\hline SIRS & solar and infrared radiation station (formerly part of SIROS) \\
\hline SMOS & surface meteorological observation station \\
\hline SORTI & solar radiance transmission interferometer \\
\hline SSP & scanning spectral polarimeter \\
\hline SST & Site Scientist Team \\
\hline SWATS & soil water and temperature system \\
\hline SWS & shortwave spectrometer \\
\hline THWAPS & temperature, humidity, wind, and pressure sensors \\
\hline TIMEx & Thunderstorm Initiation Mobile Experiment \\
\hline TLCV & time-lapse cloud video \\
\hline
\end{tabular}




\section{NOTATION (Cont.)}

TWP

UAV

UCAR

USDA

UTC

UV

UVB

UVSR

VAP

VCEIL

WSI
Tropical Western Pacific

Unmanned Aerospace Vehicle (Program)

University Corporation for Atmospheric Research

U.S. Department of Agriculture

universal time coordinated

ultraviolet

ultraviolet-B

ultraviolet spectral radiometer

value-added product

Vaisala ceilometer

whole-sky imager 


\section{SITE SCIENTIFIC MISSION PLAN FOR THE SOUTHERN GREAT PLAINS CART SITE JANUARY-JUNE 2000}

\section{INTRODUCTION}

The Southern Great Plains (SGP) Cloud and Radiation Testbed (CART) site was designed to help satisfy the data needs of the Atmospheric Radiation Measurement (ARM) Program Science Team. This Site Scientific Mission Plan defines the scientific priorities for site activities during the six months beginning on January 1, 2000, and looks forward in less detail to subsequent six-month periods. The primary purpose of this document is to provide scientific guidance for the development of plans for site operations. It also provides information on current plans to the ARM functional teams (Management Team, Data and Science Integration Team [DSIT], Operations Team, and Instrument Team [IT]) and serves to disseminate the plans more generally within the ARM Program and among the members of the Science Team. This document includes a description of the operational status of the site and the primary site activities envisioned, together with information concerning approved and proposed intensive observation periods (IOPs). The primary users of this document are the site operator, the site program manager, the Site Scientist Team (SST), the Science Team through the ARM Program science director, the ARM Program Experiment Center, and the aforementioned ARM Program functional teams. This plan is a living document that is updated and reissued every six months as the observational facilities are developed, tested, and augmented and as priorities are adjusted in response to developments in scientific planning and understanding.

With this issue, many aspects of earlier Site Scientific Mission Plan reports have been moved to ARM sites on the World Wide Web. This report and all previous reports are available on the SGP CART web site at the following location:

http://www.arm.gov/docs/sites/sgp/internal_docs.html 


\section{SUMMARY OF SCIENTIFIC GOALS AND SITE PRIORITIES}

\subsection{Programmatic Goals}

The primary goal of SGP CART site activities is to produce data adequate to support significant research addressing the objectives of the ARM Program. These overall objectives, as paraphrased from the Atmospheric Radiation Measurement Program Plan (U.S. Department of Energy 1990), are the following:

- To describe the radiative energy flux profile of the clear and cloudy atmosphere

- To understand the processes determining the flux profile

- To parameterize the processes determining the flux profile for incorporation into general circulation models (GCMs)

The Program Plan can be found in its entirety at the following online location:

http://www.arm.gov/docs/documents/project/er_0441/toc.html

The SGP CART site is the first of three global locations chosen and instrumented for data collection. As summarized in the Science Plan for the ARM Program (U.S. Department of Energy 1996), the scientific issues to be addressed specifically by using data from a midlatitude continental CART observatory include the following:

- Radiative transfer in cloudless, partly cloudy, and overcast conditions

- Cloud formation, maintenance, and dissipation

- Parameterizations of nonradiative flux

- The role of surface physical and vegetative properties in the column energy balance

- Other complications in the radiative balance in the atmosphere, particularly those due to aerosols, cloud condensation nuclei, and cloud-aerosol radiative interactions 
- Feedback processes between different phenomena and different domains

The variety, surface density, and atmospheric volumetric coverage of the SGP instrumentation are more comprehensive than those at any other ARM site, and the SGP site experiences a wider variety of atmospheric conditions than do the other sites. The resulting data accordingly support a greater range and depth of scientific investigation, making it imperative for the ARM Program to develop and maintain a high-quality, continuous data stream from the SGP site. The Science Plan can be found online at this location:

http://www.arm.gov/docs/documents/technical/sciplan/sp_contents.html

The measurements required by the Science Team, the DSIT, and the science director are categorized into areas or "working groups" of scientific applications within ARM. The DSIT and other teams coordinate activities to develop integrated, well-focused data sets for these groups. Focus areas include shortwave radiation, longwave radiation, water vapor, aerosols, clouds, surface fluxes, and the single-column model (SCM). A goal is to facilitate development of algorithms that prescribe geophysical phenomena as products of multiple data streams. More details on the activities of the working groups can be found online at

http://www.arm.gov/docs/research.html,

under "Science Team Activities."

\subsection{Priorities for Site Activities during This Period — Executive Summary}

This section represents a synopsis of activities scheduled for January-June 2000. More detail on most of the activities is contained in later sections of this document.

Intensive Observation Periods. IOPs during this period will continue to focus on (1) providing critical episodic data sets for addressing the key scientific issues proposed by the Science Team, and (2) field support for instrument development and for testing and collaborative campaigns. The IOPs scheduled for this period include the ARESE II (ARM Enhanced Shortwave Experiment II) follow-on activity of the UAV (Unmanned Aerospace Vehicle) Program (February 15-April 15), the spring SCM (single-column model) IOP (March), the Cloud IOP (March), and the Soil Sampling Campaign (May-June). See Section 5.1.2 for more details on IOPs and campaigns during this period. 
Instruments. Chris Rocken of the University Corporation for Atmospheric Research/GPS Science and Technology (UCAR/GST) is installing a 20- to 30-site GPS (global positioning system) micronetwork for water vapor tomography studies in the immediate vicinity of the central facility. If it is successful, this network will formally become part of the SGP CART site within three years. In addition, a microwave radiometer (MWR) profiler prototype will be deployed at the central facility for field testing. A normal-incidence multifilter radiometer (NIMFR) is planned for installation at the central facility to provide a time series of shortwavespectral, direct-normal irradiance measurements from which clear-sky optical depths can be inferred. Finally, a comparison study of the Vaisala RS-80 and RS-90 radiosondes is anticipated in the next six months. See Section 3.3 for more information on instrument-related activities during this period.

Facilities. The phased implementation of the Okmulgee extended facility (the wooded site) may include installation of eddy correlation (ECOR) components during this period. Phased implementation of two trailers at the IDP-4 (Instrument Development Program-4) location will be completed during this period. This area will become a general depot for storage, spare parts, repairs, and ready-to-deploy spare instruments for all three CART sites. The area is also being developed to accommodate IOP participants when the need arises. See Sections 3.7, 7.1.1, and 7.1.2 for more information on site development.

Scientific Support for Site Operations. Work to develop data quality algorithms will continue for data from longwave radiometers and the ECOR. Development of long-term statistics on data quality metrics performance will also continue. Results of data quality efforts by the site scientist can be found at the following location:

\section{http://r1.sgp.arm.gov/sst/dq_monitor/DISPLAYS.html}

The Meta Data Navigator (MDN) should be operational for broad use during this period. The Continuous Quality Improvement (CQI) Program will continue throughout the period as additional data from extended, boundary, and intermediate sites are assessed. The CQI Program focuses on site and instrument maintenance and site safety for the purpose of improving data quality. Support and guidance activities for IOPs and campaigns during the period will be provided as needed, including the development of visual displays. Guidance will also be provided to site operations staff as needed to ensure that operations and maintenance activities are carried out as smoothly as possible. Educational outreach tours of the central facility and 
talks to local groups will be provided as requested. See Sections 4 and 5.3, respectively, for more information on data quality and educational outreach. 


\section{ROUTINE SITE OPERATIONS}

\subsection{Overview}

The overwhelming majority of the measurements with the highest priority, on which the existing experimental designs are based, are regular routine observations, as specified in the Program Plan (U.S. Department of Energy 1990). Scientifically and logistically, routine operations also serve as the basis and background for all nonroutine operations, including instrument development activities, IOPs, and collaborative campaigns directed toward obtaining difficult-to-gather or expensive in situ data. Consequently, development and validation of the basic observations remain high priorities. The SGP site is sufficiently mature to support IOPs addressing key scientific areas of study.

Routine operations are the activities related to the operation and maintenance of instruments; the gathering and delivery of the resulting data; and the planning for scientific investigations, including IOPs, campaigns, value-added products (VAPs), and quality measurement experiments (QMEs). Although the site is essentially complete, instrumentation is evaluated continuously to assess its effectiveness in helping to meet the ARM Program's goals for the SGP site.

The design expectation for the routine operation of instruments is that they will continue to require servicing by site operators only once every two weeks. The exception is instruments at the central facility, which is staffed. If an instrument failed during a two-week period at an extended facility, communication, data streams, or both could be lost, although every effort is made to ensure that data-logging capacity is adequate at each location.

Site operations staff conduct additional instrument "triage" during IOPs and campaigns. The triage plan calls for IOP scientists to identify instruments, individual sensors, and communication links that are critical to the operation and goals of the IOP, so that these instruments can receive more frequent servicing than is prescribed by the routine operational requirements mentioned above. The priority of triage efforts is determined by IOP scientists, the SST, and the site program manager, who take into consideration the scientific importance of a particular data stream and its expense.

An electronics facility has been available at the central facility during the last year, so that repairs and calibrations can now be made on the site. Handling of instruments that must be 
returned to the vendor for calibration and servicing is also part of routine operations. Replacement instruments and sensors are rotated regularly to meet these requirements. Calibration and maintenance information is compiled, both to operate and maintain site instruments properly and to provide pertinent information to data users. Changeouts of all sensors and instrumentation are recorded in the site operations log.

A temperature-relative humidity calibration chamber is also available at the central facility. The system has already been used to verify calibrations of the aspirated psychrometers used during preventive maintenance checks for surface meteorological observation station (SMOS) instruments at each of the extended facilities. In addition, the chamber has been used to intercompare SGP and Tropical Western Pacific (TWP) chilled hydrometers. Steps are being taken to modify the chamber so that SGP technicians can perform and certify calibrations for temperature and humidity sensors for all three CART sites.

Initial checks of data quality after instrument installation are provided by the instrument mentors. After the mentor reviews the data stream to ensure that the acquired instrument is performing properly and that the data are identified accurately by the Experiment Center, the mentor approves a "beta" release of the data. The beta release provides data to selected Science Team members who have requested them and are willing to work with the instrument mentor on data quality issues. Beta releases are established after the instrument mentor and an appropriate member of the DSIT have created a general statement on data quality for the Experiment Center. When the data quality relative to proper instrument functionality is consistently acceptable and well documented, the mentor approves a full release of the data.

For more information about routine observations, instrument and facility logs and maps, operational status data, logistics support, instrument inventory, operations procedures and plans, and site safety, visit the Operations Management Information System (OMIS) at this location:

http://www.ops.sgp.arm.gov/ 


\subsection{Routine Operations}

\subsubsection{Functional Instruments and Observational Systems}

Figure 1 is a map of the SGP site showing the locations of the developed extended, intermediate, and boundary facilities. The status of the systems and instruments anticipated by June 30, 2000, is summarized in Table 1.

ARM has developed an instrument web site that provides a detailed description of each instrument and sensor used at each of the three CART sites. Information includes status and locations, theory of operations, calibration history, examples of data, quality assurance, and citable references. This information can be found at the following location:

http://www.arm.gov/docs/instruments.html

In addition, ARM has developed a mission-critical Meta Data System (MDS) that enables all information to be provided at a common location (supplementing the instrument data streams). The MDS database enhances the scientific utility of the instrument data streams. Such information is available at the ARM MDS web site at this location:

http://www.db.arm.gov/MDS/

Additional information about preventative and corrective maintenance of instruments, serial numbers, calibrations, etc. can be found at the OMIS web site (Section 3.1).

\subsubsection{Launch Schedule for Balloon-Borne Sounding Systems}

The schedule for routine launches of balloon-borne sounding systems (BBSSs) during this period is at 0000, 0600, 1200, and 2030 UTC (universal time coordinated). The routine radiosonde launch times, approved by the Science Team Executive Committee, were chosen to complement the National Weather Service standard launch times of 0000 and 1200 UTC and to support the daytime satellite AVHRR (advanced very-high-resolution radiometer) overpass at approximately 2030 UTC. In addition, the 2030 UTC launch, coinciding with the maximum daytime boundary layer height, supports instantaneous radiative flux (IRF) research. The midnight launch provides the only nighttime deep tropospheric information. Remote sensing of virtual temperature profiles at all boundary facilities is performed by the nearby 


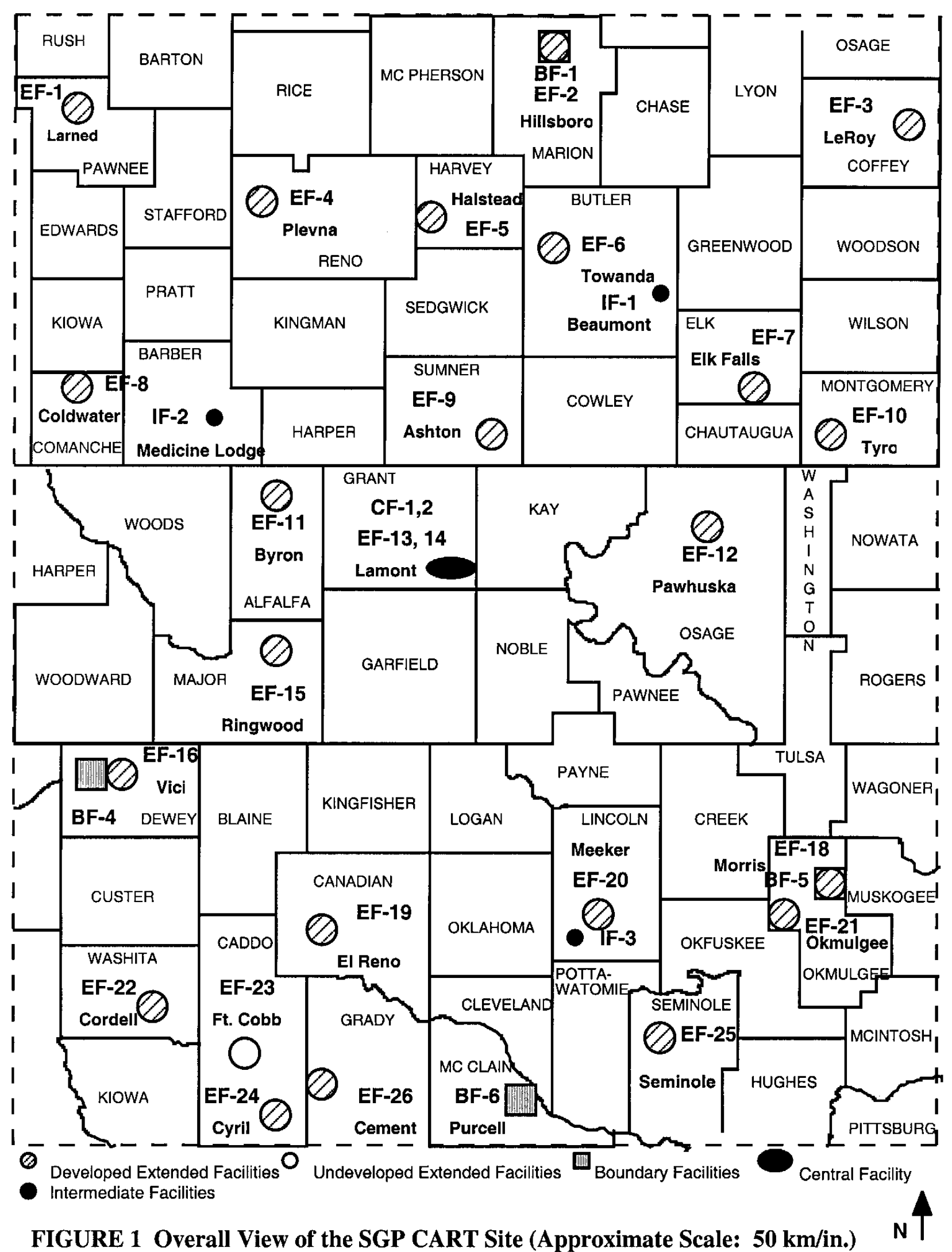


TABLE 1 Instruments and Observational Systems Anticipated at the Central, Boundary, Extended, and Auxiliary Facilities on June 30, 2000a

\section{Central Facility}

Radiometric Observations

AERI
AERI X
SORTI
BSRN
Pyranometer (ventilated)
Pyranometer (ventilated, shaded)
Pyrgeometer (ventilated, shaded)
NIP on tracker
SIRS (formerly known as SIROS)
Pyranometer (ventilated)
Pyranometer (ventilated, shaded)
Pyrgeometer (ventilated, shaded)
NIP on tracker
Pyranometer (upwelling, above pasture at $10 \mathrm{~m}$ )
Pyrgeometer (upwelling, above pasture at $10 \mathrm{~m}$ )
MFRSRs
MFR (upwelling, above pasture at $10 \mathrm{~m}$ )
Pyranometer (upwelling, above wheat at $25 \mathrm{~m}$ on
$\quad 60-\mathrm{m}$ tower)
Pyrgeometer (upwelling, above wheat at $25 \mathrm{~m}$ on
$\quad 60-\mathrm{m}$ tower)
MFR (upwelling, above wheat at $25 \mathrm{~m}$ on 60 -m tower)
CSPHOT
RSS
NFOV
NIMFR
GRAMS
SWS
RCF instrumentation, including cavity radiometers
SSP-3
USDA UVB monitoring station
USDA UV spectral radiometer

Wind, Temperature, and Humidity Systems

\section{BBSS}

915-MHz profiler with RASS

$50-\mathrm{MHz}$ profiler with RASS

MWR

IRT

Raman lidar

THWAPS

\section{Cloud Observations}

WSI (daytime/nighttime)

BLC (interim)

MPL-HR

MMCR

TLCV

\section{Central Facility (cont.)}

Others

Temperature and humidity probes at $25-\mathrm{m}$ and 60-m levels on tower

Heat, moisture, and momentum flux instrumentation at 25-m and 60-m levels

EBBR on tower

ECOR

SMOS

AOS (samples at $10 \mathrm{~m}$ )

SWATS

\section{Extended Facility Components}

SIRS (formerly known as SIROS)

Pyranometer (ventilated)

Pyranometer (ventilated, shaded)

Pyrgeometer (ventilated, shaded)

NIP on tracker

Pyranometer (upwelling, at $10 \mathrm{~m}$ )

Pyrgeometer (upwelling, at $10 \mathrm{~m}$ )

MFRSR

EBBR or ECOR

SMOS

SWATS

Auxiliary Facilities

None in preparation

Boundary Facilities

BBSS

MWR

THWAPS

VCEIL

AERI

\section{Intermediate Facilities}

915-MHz profiler and RASS 


\section{TABLE 1 (cont.)}

a AERI, atmospherically emitted radiance interferometer; AOS, aerosol observation system; BBSS, balloon-borne sounding system; BLC, Belfort laser ceilometer; BSRN, Baseline Surface Radiation Network; CSPHOT, Cimel sunphotometer; EBBR, energy balance Bowen ratio; ECOR, eddy correlation; GRAMS, ground-based radiometer autonomous measurement system; IRT, infrared thermometer; MFR, multifilter radiometer; MFRSR, multifilter rotating shadowband radiometer; MMCR, millimeter cloud radar; MPL-HR, micropulse lidar-high resolution; MWR, microwave radiometer; NIMFR, normal-incidence multifilter radiometer; NFOV, narrow-field-of-view zenithpointing filtered radiometer; NIP, normal-incidence pyrheliometer; RASS, radio acoustic sounding system; RCF, radiometer calibration facility; RSS, rotating shadowband spectrometer; SIROS, solar and infrared radiation observing system; SIRS, solar and infrared radiation station; SMOS, surface meteorological observation station; SORTI, solar radiance transmission interferometer; SSP, scanning spectral polarimeter; SWATS, soil water and temperature system; SWS, shortwave spectrometer; THWAPS, temperature, humidity, wind, and pressure sensors; TLCV, time-lapse cloud video; USDA, U.S. Department of Agriculture; UV, ultraviolet; UVB, ultraviolet-B; VCEIL, Vaisala ceilometer; WSI, whole-sky imager.

National Oceanic and Atmospheric Administration (NOAA) profilers, which are being outfitted with ARM-provided radio acoustic sounding system (RASS) units. The RASS units have already been installed at the Purcell, Oklahoma, and Haviland, Kansas, NOAA profilers. The Lamont, Oklahoma, NOAA profiler will not receive a RASS unit because the location is too close to a residence, but the nearby SGP CART site central facility collects a relative abundance of thermodynamic data. In addition, GPS instruments were recently installed at the Purcell, Vici, Haskell, Haviland, Lamont, Neodesha, and Hillsboro NOAA profiler locations to provide estimates of precipitable water. This information, along with the NOAA profiler data, has become available to the ARM Program as external data.

The central facility is staffed from 0530 to 2030 CDT (central daylight time) (0430-1930 CST [central standard time]) and from 2330 to 0330 CDT (2230-0230 CST), Monday through Friday (including holidays, although staffing is limited). During normal SCM IOPs, the central facility and the four boundary facilities will be staffed 24 hours per day, 7 days per week (including holidays) to facilitate round-the-clock radiosonde releases every 3 hours, centered on 0000 UTC. 


\subsection{Instruments}

A CART instrument is any instrument that is approved by the ARM Program and for which the site operations management has accepted responsibility for operation and maintenance. The Pre-Readiness Review and Operational Readiness Review forms represent requests for information to facilitate the installation and operation of instruments or facilities at the SGP CART site. The purpose of such reviews is to achieve an efficient handoff of instruments and facilities from instrument mentors to site operators. When all procedures, operation manuals, and training pertaining to an instrument have been completed, the instrument is accepted by site operations management. If sufficient documentation is available to operate an instrument, even though more will ultimately be required for full acceptance, the instrument may be operated in a degraded mode. The SGP CART instrumentation implementation flow chart is provided elsewhere (page 17 in Peppler et al. 1999).

Instruments recently installed or expected to be installed during this period include the following:

- Ultraviolet Spectral Radiometer(UVSR), Completed. A UVSR (Lee Harrison, State University of New York-Albany, with funding from the USDA) was installed in October 1999. This instrument will measure total horizontal irradiance at 290-360 $\mathrm{nm}$.

- Global Positioning System, in Progress. Chris Rocken of UCAR/GST is in the process of installing a 20- to 30-site GPS micronetwork in the immediate vicinity of the central facility. Approximately half of the instruments were installed in fall 1999, and the rest are expected to be installed by summer 2000. These water vapor measurement devices will be used to test water vapor tomography techniques. This is a Science Team project, and proof of concept is anticipated to take about three years. If it is successful, the network will become part of the formal SGP CART site domain.

- Small Business Innovative Research (SBIR) Program Microwave Radiometer, in Progress. The U.S. Department of Energy (DOE) SBIR Program has awarded a Phase II grant to Radiometrics to test a prototype MWR temperature and water vapor profiler system at the SGP CART site. Installation of this system is planned for 
February 2000. The MWR profiler will provide tropospheric profiles of temperature and water vapor for nonprecipitation conditions.

- Normal-Incidence Multifilter Radiometer, in Progress. A NIMFR is planned for installation at the central facility by May 2000. The instrument is a ground-based radiometer that provides a time series of the shortwave-spectral, direct-normal irradiance. In addition, a broadband silicon detector can crudely measure the directnormal irradiance. These irradiance measurements can be used to infer clear-sky optical depth and columnar abundance of ozone and water vapor.

- Upgrades of the Balloon-Borne Sounding System, in Progress. Steps have been taken to upgrade the CART BBSSs to use GPS-based rather than loran-based tracking for determining position, a necessity during the next few years as loran-C transmitters are phased out. In addition, a new type of Vaisala radiosonde, in which the RS-90 sonde replaces the RS-80 version presently used, is expected to become available this year. The humidity sensor on the RS-90 sonde is reported to have a faster response and to recover more quickly after it emerges from clouds. The temperature sensor is smaller and thus is probably considerably faster in response and less susceptible to the effects of heating by solar radiation. Reference temperature, humidity, wind, and pressure sensors will be operational at each of the four boundary facilities by fall 2000 .

\subsection{Baseline Change Request}

Once site operations personnel have accepted instruments, their design and configuration are "locked in" by using a configuration management system that is controlled by site operations personnel. Any modifications to instruments or data systems that could affect more than one ARM functional group require a baseline change request (BCR). The BCR process is in a secure web-based system. A BCR submittal form can be found at this site:

http://www.twppo.lanl.gov/oms.acgi\$bcr.form.sgp

The $\mathrm{BCR}$ requests usually come from instrument mentors. The site program manager, the control point for the BCR process, assigns infrastructure support for review and approval. Individuals participating in the review and approval process are given passwords for access to the BCR database. An emergency BCR requires response within 24 hours, a critical BCR within 
24-48 hours, a very important BCR within 3-5 working days, an important BCR within 5 working days, and a routine BCR within 10 working days.

\subsection{Development of the Site Data System}

Several installed instruments and all new instruments require software to transfer the data from the instrument platforms to the site data system (SDS) via a pathway referred to as the integrated data processing circuit (IDPC). The IDPC handles communications between the instrument and data loggers and the data ingest system, transfers reports on instrument status to site operations staff and others, and transmits data to the Experiment Center and the Data Archive. The IDPC development schedule and the status of instruments can found at this location:

http://www.res.sgp.arm.gov/trav/idpc_gen_info.htm

\subsection{Observations, Measurements, and External Data}

External data being delivered to the ARM Program can be found at this web site:

http://www.xdc.arm.gov/

The availability of data from a particular platform on any given day is a function of the quality assurance process; some segments are temporarily unavailable during evaluation or correction of problems.

\subsection{Site Development Activities during This Period}

A major activity was the replacement of 22 SMOS towers at the extended facilities and the central facility. The new towers are lightweight, single-mast, counter-weighted, tipping structures that require no guy anchors. The replacement activity was led by Dan Nelson, and Wayne Meadows was the technical safety representative in the field. A subcontractor installed the new towers. The activity was completed in September 1999.

The Cordell extended facility was relocated in December 1999 because of new road construction. The new location is about $100 \mathrm{~m}$ west of the former location. The soil water and temperature system (SWATS) and the associated rain gauge remained at the previous location 
and was linked to the new site by fiber-optic cabling. The Oklahoma Department of Transportation subsidized the move. Dan Nelson was in charge of the project.

A walk-up scaffolding tower (approximately $18 \mathrm{~m}$ ) was erected in the summer of 1997 at the Okmulgee extended facility. The tower supports an ECOR system, a SMOS, and a solar and infrared radiation station (SIRS) above the forest canopy. All infrastructure support was completed in May 1998. Phased implementation of the SMOS and SIRS is planned for February 2000.

Two new trailer systems will be added to the central facility: the instrument maintenance facility (IMF) trailer and the guest instrument facility (GIF) trailer. The IMF is a triple-wide Argonne surplus trailer that will provide a 36-ft by 66-ft facility for consolidating instrument parts, repairs, and an electronics laboratory, as well as for additional office space and restrooms. This facility will be located just east of the conference trailer and southwest of the IDP-3 location. The GIF is a double-wide Argonne surplus trailer that will provide a $24-\mathrm{ft}$ by $52-\mathrm{ft}$ space for guest instruments, to be located just north of the optical trailer. These trailers have been shipped to the SGP CART site, and the implementation design phase is nearly complete. The trailers will be operational in time for the March 2000 IOP activities.

In anticipation of the need for additional IDP area facilities, the IDP-4 location was developed. This 150 -ft by 175 -ft graveled area is at the site formerly occupied by the farmhouse at the extreme southeast corner of the central facility. This area has a double-wide trailer ( $24 \mathrm{ft}$ by $55 \mathrm{ft}$ ) for storage and an office trailer (12 ft by $50 \mathrm{ft}$ ). The storage facility will serve all three CART sites for ready-to-deploy spare instruments and instrument spare parts. The site is expected to be completed by early spring 2000 . 


\section{DATA QUALITY}

Data quality issues are addressed at several levels within the ARM Program and at the SGP CART site. One of the primary goals of the ARM Program is to provide data streams of known and reasonable quality. Maintaining data quality for a program of this size and complexity is a significant challenge. Data quality assurance within the ARM Program infrastructure has matured over the past few years and will continue to evolve, with the SST continuing to play a significant role. Data flagging issues, development of a mechanism for displaying information on data quality to data users, and addressing data quality for new instruments continue to be the focus for this six-month period.

\subsection{Instrument Mentors}

Instrument mentors are charged with developing the technical specifications for instruments procured for the ARM Program. The instrument mentor then tests and operates the instrument system (either at his or her location or at the SGP CART site). In addition, the mentor works with SDS personnel on data ingest software requirements as part of the IDPC. Data ingest involves the conversion of data streams to the International System of Units (SI), as well as the acquisition of parameters that can be used to monitor instrument performance (e.g., monitoring an instrument's output voltage for a 5-V power supply or the continuity of the wire in a hot-wire anemometer). Data collection and data ingest, then, are the focus of the first level of data quality assurance. Quality at this level is monitored routinely by instrument mentors and site operators.

The next level of data quality assurance involves beta release of data streams from individual instruments. The mentor receives the data from the instrument to determine whether the technical specifications of the instrument are being met. When the mentor is satisfied that the instrument is functioning properly and that the technical specifications have been met, the data are formally released to the Science Team and other data users. After this release, the instrument mentor is charged with reviewing the instrument data streams at least once every two weeks, an action monitored at the Experiment Center. This information is forwarded to the SST.

Instrument mentors provide all calibration, operations, and maintenance documents and lists of spare parts to site operations. Typically, the mentor provides additional detailed documentation and hands-on training so that appropriate support can be offered by site operators. 
This activity is part of the Operational Readiness Review process. More details on instruments or data quality activities can be found at

$$
\text { http://www.arm.gov/docs/sites/sgp/sgp_instruments.html }
$$

under the listings for individual instruments.

\subsection{Site Scientist Team}

The SST helps to ensure that the scientific productivity of the SGP CART site is maximized by both the routine and special (IOP) operations at the site.

Data quality assessment efforts of the SST involve evaluation of individual and multiple sets of data streams as needed, on an exploratory or developmental basis (data quality investigations); participation in QMEs; and participation in the development of QMEs and VAPs.

The comprehensive, systematic assessment of SGP data stream quality is manifested in several ways, including the development of automated graphic display techniques for use by the SST in daily monitoring of data quality (initiated in October 1995), the development of performance metrics that systematically determine the percentage of the collected data falling within given quality tolerances (initiated in February 1996), and evaluation of the calibration and maintenance information.

The development of performance metrics is aimed at determining the quality of the site data via time series (numerical and graphic) of the metrics. In late 1996, the SST began issuing assessments of the data from several instruments, with the goal of quicker resolution of instrument and data quality problems. A web site containing automatically generated graphic displays of performance metrics and other quality assessment techniques is at this location:

http://r1.sgp.arm.gov/sst/dq_monitor/DISPLAYS.html

This display, established in 1998, contains up-to-date information on the quality of SGP data streams. 
Plans for this six-month period include continued development of graphic display techniques and performance metrics for SIRS broadband longwave data and ECOR data. The SST is also constructing summary statistics describing the performance of long-term metrics. See Peppler and Splitt (1998) for more information about ARM SGP data quality techniques.

\subsection{Value-Added Products and Quality Measurement Experiments}

Unlike many other scientific projects, ARM collects data in an ongoing, continuous manner. Because of the volume of the perpetual data streams, traditional case study methods for analyzing the data are not very effective. To meet the need for an automated analytical approach, the concept of a VAP was defined. A VAP creates a "second-generation" data stream by using existing ARM data streams as input and applying algorithms or models to them. A VAP is run continuously in the ARM Experiment Center, and the output generated is treated as a new ARM data stream. The VAPs in the special class called QMEs compare different data streams for consistency and allow for continuous assessment of the quality of the data streams. These data streams may come from direct measurements, measurements derived from instrument observations via other VAPs, or model output that is currently created by other VAPs.

More information on development and on specific VAPs and QMEs is available on the web at this location:

http://www.arm.gov/docs/research/vap_homepage/vap.html

\subsection{Meta Data Navigator}

The tasks of (1) incorporating what is known about data availability and data quality and (2) linking this knowledge directly to individual measurements in a way that is easily identifiable by data users, such as by data flagging, continue to be accomplished through development of the MDN, part of the ARM information architecture.

Within the MDN, a communication interface about data availability is being established by color-coding measurements obtained from a particular instrument with different colors to indicate the availability of data and the quality of the data (for a daily aggregate). Pointers direct the data user to details of the particular data quality inspection methodology for each measurement. For example, all existing data are color-coded white. Missing data are color- 
coded black. Data reviewed by an instrument mentor and judged to be of acceptable quality are green. Suspect data values are yellow. Data identified as not usable are red. The color of the data changes to reflect the current view of the quality of the measurement. The entire process is automated with a manual override capability. The first version of the MDN, delivered in March 1999, contained all of these features. In addition, a plan is being defined to assign a data quality flag to each existing data value. Quick-look plots will also be included in the MDN, version two which is to be completed in 2000. These plots are intended to provide the data user with a visual data inspection capability, especially if data are color-coded yellow and require further inspection and interpretation.

\subsection{Problem Review Board}

The problem-reporting system has several components. The process begins with the completion and submission of a Problem Identification Form (PIF). The PIFs are received by the Problem Review Board (PRB), which is composed of representatives from the DSIT and the IT, along with the site program managers. The PRB meets weekly via teleconference and assigns responsibility for analysis and resolution. Resolution is documented in a Corrective Action Report (CAR). A copy of the CAR is sent to the originator of the PIF to ensure that resolution of the problem is communicated.

In addition, a Data Quality Report (DQR) may be required. A DQR is a statement about the quality of data from a particular instrument. The information could be quite simple (e.g., stating that an instrument system was turned off and the data do not exist) or quite complex, giving detailed analyses and equations that should be used to adjust the instrument's data. Hence, the description of the problem and the solution must be complete, so that someone can correct the data accurately.

The PIF, CAR, and DQR forms are accessible from multiple points on the ARM web site. The PIF/CAR/DQR database can be found at the following location: 


\section{SCIENTIFIC INVESTIGATIONS AND OPPORTUNITIES}

\subsection{Intensive Observation Periods}

The SGP CART site operates a vast suite of instrumentation that routinely provides continuous data streams at a prescribed rate. These rates, however, can be changed upon request. Requests from inside and outside the ARM Program can be made either (1) to operate an ARM instrument or instruments at a different data collection rate or in a different mode of operation or (2) to support and compare non-ARM instruments with ARM instruments. Such periods of special operation are referred to as IOPs.

\subsubsection{Scheduling IOPs}

Requests for IOPs may come through the ARM Program management office (technical director), the SGP CART site program manager's office, or both. The initial requests may be made informally, but an abstract of the goal(s) of the experiment(s) being requested, a list of the potential instruments and platforms involved, and the time period of the experiment(s) must be provided for approval. The requester must identify points of contact for coordination.

Approval of an IOP is an external process that requires (1) review for resources and relevancy and (2) approval by the ARM Program technical director, the SGP CART site program manager, the SST, and site operations staff. After approval, the management of the detailed operational planning, setup, conduct, and shutdown of the IOP is the responsibility of the site program manager. An IOP is given a title and assigned a DSIT representative, who has the responsibility to obtain the relevant scientific information about the proposed activity, typically in a science plan. The DSIT representative informs the appropriate ARM Science Team members of the proposed activity for the purpose of potential collaboration. The site program manager obtains from the DSIT representative a list of potential principal investigators (PIs) and the instruments or systems that are intended to be located at the SGP CART site. The site program manager has PIs fill out IOP questionnaires to collect information about the operational, safety, and data requirements of the IOP. The IOP questionnaires are posted on the IOP web site, and appropriate ARM infrastructure personnel are notified for review. The IOP questionnaire can be completed electronically by a PI at this web location:

http://www.arm.gov/stdocs/internal/iop_form.html 
A complete description of past IOPs is on the web at this location:

http://www.arm.gov/docs/iops.html

\subsubsection{IOPs and Campaigns Scheduled for This Period}

Details on IOPs and campaigns planned or proposed for this period can be found on the web at this location:

\section{http://www.arm.gov/docs/iops.html}

Synopses of these events are given below.

Photoacoustic Campaign (February 21-March 17, 2000). A proof-of-concept study will be conducted to see how the use of complementary methods can improve confidence in aerosol light absorption measurements. Aethelometers, nephelometers, and particle soot absorption photometers (PSAPs) will be installed in the aerosol observation system (AOS) at the central facility to compare results with instruments currently being used at the SGP CART site.

ARESE II (February 21-April 15, 2000). The UAV Program will be conducting an ARESE II IOP in early spring 2000. This activity will focus on heavy stratus clouds, with only the Twin Otter flying repeatedly over the central facility, and will be performed in conjunction with the Cloud IOP. The purpose is to address unresolved issues from the original ARESE experiment by (1) significantly increasing the number of thick-cloud cases studied (e.g., looking for four to six good-data days); (2) providing additional spectrally resolved measurements; and (3) where possible, including two independent (different) instruments to measure key properties such as broadband fluxes and spectral radiance's. The first science flight is scheduled for February 21, 2000, and the last is scheduled for March 31, 2000. If the deployment is extended for some reason, the last science flight could take place as late as April 15, 2000. The issue of which activities will occur at the Blackwell-Tonkawa Airport versus the Ponca City Airport is still to be resolved.

Cloud IOP (March 1-21, 2000). The Cloud Working Group will deploy a number of vertically pointing and scanning lidars and millimeter radars within a mesoscale region around the central facility, where the three-dimensional (3-D) structure of the cloud fields will be 
measured intensively during the study period. The statistics of the radioactive forcing within a mesoscale model grid box are quite sensitive to the 3-D structure of hydrometeor properties. In addition to the surface-based instrumentation, data will be collected from aircraft platforms. The aircraft participating include the University of North Dakota Cessna Citation, the UAV Twin Otter, the Spec Lear jet, and the National Aeronautics and Space Administration (NASA) ER-2.

Spring SCM IOP (March 1-21, 2000). The SCM Working Group has requested the first of three three-week SCM IOPs in March of 2000 to coincide with the Cloud IOP study period.

EOS MOPITT Validation Exercise (MOVE) (May 8-28, 2000). The Earth Observing System (EOS) Terra satellite was successfully launched on December 18, 1999, from Vandenberg Air Force Base. The Measurements of Pollution in the Troposphere (MOPITT) instrument is one of those aboard Terra. MOVE is the validation of MOPITT. Instruments and platforms involved include (1) the DOE Citation aircraft flights over the SGP CART site central facility and surrounding area at 39,000 ft, carrying remote sensing instruments to measure tropospheric carbon monoxide, (2) Twin Otter flights that spiral up and down from near the surface to $20,000 \mathrm{ft}$ over the central facility, obtaining measurements of carbon monoxide, carbon dioxide, methane, and HF6; and (3) a ground-based grating spectrometer.

Soil Sampling Campaign (May 15-30, 2000). The Soil Sampling Campaign (Jim Happell, University of Miami) will investigate the possibility that soils are a significant global sink of atmospheric carbon. Soil gas samples, collected at 5-cm depth intervals over the top $50 \mathrm{~cm}$ of soil, will be drawn through a small probe into syringes. Carbon tetrachloride and methyl chloroform concentrations in the soil gas will be measured on-site by gas chromatography. The decrease in concentration of these gases with depth in the soil will be used to calculate the uptake rate from the atmosphere. Supporting measurements will include soil moisture, soil temperature, soil porosity, and soil organic carbon content. Environmental levels of various halocarbons will also be investigated.

\subsection{Scientific Working Groups}

The ARM Program has formed groups concentrating on the study of geophysically significant phenomena such as water vapor (atmospheric state), aerosols, clouds, and radiation. Development of algorithms to describe these phenomena is currently a primary focus. 
One goal of these groups is to produce algorithm products that represent a merging of appropriate instrumental measurements into a cohesive whole defining a particular geophysical state, for use by the Science Team. These products specifically address problems posed in the Science Plan (U.S. Department of Energy 1996) and by the various science applications working groups. More information on the activities of the working groups can be found under "Science Team Activities" at the following location:

http://www.arm.gov/docs/research.html

\subsection{Educational Outreach}

The educational outreach program for the SGP CART site, coordinated by Ken Crawford, Director of the Oklahoma Climatological Survey, combines a range of resources available at the University of Oklahoma. Outreach is focused at the precollege, undergraduate, and graduate levels. Efforts in this six-month period will concentrate on professional development activities, staff support for teacher participants, scientific mentorship of students, development of data analysis tools for students and teachers, and application of data in the classroom (McPherson and Crawford 1996; Melvin and McPherson 1998). A two-week workshop involving five Kansas and two Oklahoma teachers was held at the university in July 1997. Instruction was given on how to use ARM data and related software, along with lessons on atmospheric radiation, energy transfer, meteorological data, telecommunications, data visualization, the Internet, and the ARM Program. Six EARTHSTORM teachers attended the workshop as the "Storm Team," helping instruct participants and offering insight on ways to modify existing lessons and materials to incorporate ARM data. The five Kansas teachers were given Power Macintosh 5400 computers for their classrooms. The Storm Team and other ARM teachers made presentations at the 8th Symposium on Education, held at the 79th Annual Meeting of the American Meteorological Society in Dallas, Texas, in January 1999.

An EARTHSTORM/ARM/Oklahoma Mesonet teacher workshop was held at the University of Oklahoma July 26-27, 1999. Schools can access ARM data at this location:

http://www.arm.gov/docs/education.html

An SGP-only outreach site can be reached from this location through the link "Outreach Sites," by selecting "Southern Great Plains," or by going directly to this location:

http://outreach.ocs.ou.edu/arm/ 


\section{DISTRIBUTION OF DATA}

Most of the data currently being requested are received from the SGP CART site or external data sources and are then repackaged for daily and weekly distribution to individual users. In some special cases, users can log into the Experiment Center or the R1 computer at the central facility and extract data by anonymous file transfer protocol (FTP). All data are sent to the Data Archive, where they are accessible to the public at this web site:

http://www.archive.arm.gov

The status of data streams from CART instruments and external sources has been classified as follows:

- Releasable - released upon request for the data stream.

- Developmental — released only to SDS personnel for development of ingestion programs.

- Under evaluation - released to an investigator for an initial data quality check.

- Beta release - releasable and of known, reasonable quality.

- Collecting — during collection of raw data for future processing and distribution.

- Mentor only — provided only to the instrument mentor at the request of the mentor.

- Analysis - released for further processing or analysis, such as for graphic display.

- Defunct - obsolete due to replacement of a prototype instrument data stream with the CART instrument data stream. 


\section{LOOKING AHEAD}

The SGP CART site now provides a full range of data streams needed to support the broad spectrum of Science Team research. Research activities increasingly draw on multiple SGP data streams to focus on geophysically significant phenomena (water vapor profiles, clouds, aerosols, temperature profiles, radiation, surface fluxes). The most important operational challenges during 2000 and beyond will therefore include maintaining the performance of the basic instrumentation suite at the highest possible level and improving that performance where possible, enhancing the original CART design through the permanent addition of new instruments, evaluating the effectiveness of current instrumentation, and mounting focused IOPs and campaigns involving temporary additional instrumentation. These activities can meet the evolving scientific requirements, challenges, and opportunities for the SGP CART site. Here we outline the path ahead and issues for 2000 and beyond, to the extent possible in late 1999.

\subsection{Routine Operations}

\subsubsection{Instruments and Measurements}

Suominet. The University of Oklahoma is planning to submit a proposal to Suominet for the installation of a two-channel GPS at 15 extended facilities. In addition, the Geography Department will provide for geodetic-quality installation to support plate techtonic studies. The GPS information will also be used by the Meteorology Department for a lightning detection and positioning network. Randy Peppler is the primary ARM contact. The proposal is due by April 2000.

Aerosol Observation System. Scientists at the NOAA Pacific Marine Environmental Laboratory (PMEL) will use the central facility AOS trailer to measure selected chemical properties of the aerosols sampled through the AOS inlet. Filters will be used to collect daily samples of submicron particles for analysis of total aerosol mass and of major anions and actions by ion chromatography. In addition, filters will be collected weekly for similar analyses on particles with diameters of about 1-10 $\mu \mathrm{m}$. PMEL will conduct the analyses and post the results on a web site and preferably will provide the data to the ARM External Data Center. ARM personnel have assessed the costs of assistance with installation and operation of the aerosol collection equipment. Although the aerosol chemistry systems required for filter sampling are in place and site operations personnel have been trained in the procedures, PMEL has not implemented the activity. 
Aerosol Observation System by Aircraft (AOSAIR). Routine in situ measurements of boundary layer aerosols over the central facility will be made by using a light aircraft. The aircraft will be based in the local area. Flights are expected to begin in early spring 2000.

Cavity Radiometer. Continuous direct-beam solar irradiance measurements by a cavity radiometer remain under discussion. Documentation for the Baseline Surface Radiation Network (BSRN) specifies that an all-weather, windowless cavity radiometer is to be operated at a BSRN site. Because of dusty conditions at the central facility, this is not immediately feasible. Operation of a windowed cavity radiometer might be possible at the radiometer calibration facility (RCF), but considerable effort would be needed for continuous operation. Some compromise for part-time or discontinuous operation might be required. Cavity radiometers were operated at the RCF during the Fall 1997 Integrated IOP and during past BORCAL (Broadband Outdoor Radiometer Calibration) operations.

Cloud and Aerosol Optical Depths. The Cloud Working Group would like to see routine computation of cloud optical depth across the CART site. This quantity, which links cloud properties to radiation, could be retrieved from the multifilter rotating shadowband radiometer (MFRSR). At the central facility, this quantity could be retrieved from a number of instruments, including the Cimel sunphotometer (CSPHOT). Likewise, aerosol optical depth could be computed.

Cimel Sunphotometer. More angular information could be recorded from the CSPHOT. At present, the instrument scans up to 40 degrees on each side of the sun. The additional angular information would be helpful to the Shortwave Working Group.

Ground-Based Radiometer Autonomous Measurement System (GRAMS). Calibrations for the total broadband solar radiometers were completed in early 1999, and plans were made to implement the calibrations to begin producing appropriate data streams. The GRAMS has been fielded for nearly two years without production of calibrated values. Work continues on arranging for calibrations and acquisition of new filters for the fractional solar broadband radiometers. Operation of one GRAMS instead of two has been suggested.

Multifilter Rotating Shadowband Radiometer. Improvements to the MFRSRs at the central facility are planned for this period. The improvements to be made will mitigate problems involving filter drift, characterization of the cosine responses of the heads, initial calibrations, 
temperature sensitivity, and alignment. This level of effort has been determined to be excessive for MFRSRs at all extended facilities. As MFRSR units fail at extended facilities, they will be removed from service via the BCR process.

Millimeter Cloud Radar (MMCR). Brookhaven National Laboratory reports that each step in the calibration adjustment process is being reviewed to ensure that the data reprocessing strategy being conducted for the MMCR is sound. Work continues on mitigating the effects of insects on radar returns.

Optical Transmissometer. A commercially available transmissometer might be acquired to detect fog, dust, and drizzle too light to be recorded by rain gauges. Such phenomena are best detected by open-path devices rather than through a large sampling stack like that used by the AOS. The data generated by such an instrument would be useful for evaluating signals from radars, lidars, and the MWR.

Ozonometer. The use of a hand-held ozonometer is under consideration. Such a device, used during the Fall 1997 Integrated IOP, can make relatively easy observations of ozone.

Passive Microwave Systems. A passive MWR for obtaining profiles of temperature through clouds could augment profile measurements made with the atmospherically emitted radiance interferometers (AERIs) at the boundary facilities. The primary advantage of microwave profiling is that it penetrates clouds, unlike any of the other remote sensing systems for water vapor currently in use at the SGP. The DOE SBIR Program has awarded a Phase II grant to Radiometrics to field-test an MWR, a temperature and water vapor profiler that is expected to be deployed at the SGP CART site in early 2000 for testing.

Eppley 8-48 Pyranometers. An Eppley 8-48 pyranometer was installed at the central facility's SIRS testbed in early 1999. This radiometer replaced the testbed's shaded precision spectral pyranometer (PSP) for a field evaluation of effectiveness. Work at the National Renewable Energy Laboratory and elsewhere has confirmed that shaded PSPs are subject to offsets in the measurement of diffuse radiation. The Eppley 8-48 is engineered to minimize this offset. In addition to use of this device in place of the shaded PSPs, other options for improving diffuse measurements are being addressed (Dutton et al. 2000). 
50-MHz Radar Wind Profiler (RWP). Experiments involving the improvement of 50-MHz RWP data were conducted in April 1999 for the MCS (Mesoscale Convective Systems) Campaign. The usefulness of these data in particular continues to be discussed. Because this RWP system has had some problems during the past two or three years, care in evaluation of data quality is required to avoid using data collected during problem periods. Rich Coulter, Dave Turner, and Ed Westwater have agreed to evaluate the performance of the 50-MHz system during a selected time period, by the end of December 2000, to generate a recommendation on the future of the system at the SGP.

Solar radiance transmission interferometer (SORTI). Long-term operation of the SORTI at the central facility is under discussion. Additional resources would be needed for routine operations. A significant question is whether SORTI data will be used effectively by ARM Science Team members.

Spectral Radiometry. The shortwave spectrometer (SWS) and the rotating shadowband spectrometer (RSS) still run too infrequently for the purposes of the Shortwave Working Group. The SWS has experienced frequent measurement difficulties, while the RSS is often off-line for several months at a time for calibration. Installation of the Colorado State University scanning spectral polarimeter (SSP-3), which has been scheduled for months, is necessary for required redundancy at the central facility.

Surface Bidirectional Reflectance. Measurements of surface bidirectional reflectance have been suggested at times for the SGP site. A commercial portable apparatus for rapid acquisition of bidirectional observations of land and the atmosphere (PARABOLA) is available, but the system is not suitable for routine observations. Nevertheless, such observations would be quite useful in interpreting solar reflectances from satellites. A Science Team project is now assessing this observational need.

Soil Water and Temperature System. Long-term maintenance plans are being developed for the SWATS, and a full release of the three remaining sites is anticipated within this sixmonth period. Degradation issues are starting to surface now that the instruments have been fielded for three years.

Whole-Sky Imager. A draft data release statement has been issued for the whole-sky imager (WSI) at the central facility. Much of the statement is applicable to all ARM WSIs. Data 
being released include calibration files, calibrated radiances with $35-\mu$ sr resolution for selected sky patches, calibrated-radiance sky images for daytime and nighttime conditions, calibrated-radiance sky movies for daytime and nighttime, summary statistics of patch radiances, calibrated radiances with $35-\mu$ sr resolution for the full suite of spectral channels, classifications of sky dome with $35-\mu$ sr resolution into ten categories describing cloud and aerosol conditions, images using false colors to represent the ten categories for daytime or nighttime, and a summary compilation of classification by category and viewed area. Some problems remain with the classification during periods when the solar zenith angle is between 80 and 100 degrees. In addition, SGP WSI calibration for zenith angles greater than 80 degrees is suspect, a problem that affects both the radiance products from this site for these angles and also the classification products.

Platt Radiometer. Martin Platt's three-channel, narrowband infrared radiometer, used in conjuction with the SGP micropulse lidar, will provide information on cloud physics properties. Because of development complications, Martin Platt has delayed deployment until midsummer 2000.

\subsubsection{Facilities}

Additional Extended Facilities at the SGP CART Site. Some concern has been expressed that the spatial coverage of the extended facilities seems incomplete for measuring air-surface exchange rates of heat and moisture, particularly to the south and southeast of the central facility. The final disposition of the planned Ft. Cobb extended facility has not been determined.

\section{Local Observations of Surface Vegetative Conditions at Extended Facilities. The} interpretation of data on, and the modeling of, surface latent and sensible heat fluxes at extended facilities would be assisted by routine observation of leaf area index and surface optical reflectance properties, represented by the non-dimensional vegetative index (NDVI). Relatively simple devices that measure NDVI can be obtained at modest cost. Local measurements of NDVI are believed to be particularly important for interpreting NDVI values derived from remote sensing data obtained by satellites. With local NDVI data, the satellite data could be used to help infer the values and variability of surface heat fluxes over the CART site. This issue remains under discussion. 


\subsubsection{Operations}

The following open questions are on the table concerning the operation of the SGP site and its cost-effectiveness:

- SCM IOPs. Are three SCM IOPs still required each year at the SGP site? When will remote sensing be sufficient to replace sondes? Do SCM IOPs need to be 21 days long?

- Extended Facilities. Are all 24 extended facilities necessary for adequate surface characterization for GCMs? Do we still need to visit extended facilities every two weeks?

- Aerosol Observation System. Does the AOS provide sufficient information to study the role of aerosols in radiative transfer in GCMs?

- Eddy Correlation. Should ECOR instrumentation be decreased at or eliminated from extended facilities?

- Routine Sonde Launching at the Central Facility. Are four launches per day enough? Should we launch seven days per week instead of the current five?

\subsection{IOPs and Campaigns}

Planning, discussion, or both are under way for a number of proposed IOPs and campaigns for the 2000-2001 time frame, beyond this period. The proposed activities are discussed below.

AFWEX (September 2000). For fall 2000, the Water Vapor Working Group has proposed its third Water Vapor IOP, to be known as the ARM-FIRE Water Vapor Experiment (AFWEX). The IOP will focus on (1) upper tropospheric water vapor measurements, (2) absolute instrument calibration, and (3) an international radiosonde intercomparison. For the upper troposphere, the working group is seeking the participation of the NASA DC- 8 to carry differential-absorption lidar (DIAL), high-resolution interferometer spectrometer, and Lidar Atmospheric Sounder Experiment water vapor systems and also to make radiance and sunphotometer observations for up to 40 hours of missions. ARM remains in negotiation with NASA over use of its platforms, 
particularly the DC-8. Desired ground-based measurement platforms include the Jens Boesenberg DIAL, the NASA Goddard Space Flight Center scanning Raman lidar, Ed Westwater and Jet Propulsion Laboratory MWRs, and dual sondes. A number of NASA chilledmirror sondes might be launched during this IOP.

DIAL/Raman Lidar Validation Intercomparison Campaign (September 2000). The ARM Program has arranged to have the Boesenberg DIAL system (Germany) at the CART site for participation in AFWEX. The system will be used for another intercomparison and validation of the CART Raman lidar. Dave Turner at Pacific Northwest National Laboratory (509-375-2590) is the primary contact for this activity.

UAV IOP (September 2000). The UAV IOP will be a top-of-the-troposphere mission involving the Altus UAV, perhaps flying above 50,000 ft. This mission will seek to close the "top-of-the-box" problem. Improved operational robustness of both the Altus and ground operations will be the key to this mission. The mission will consist of a simplified flight pattern and much less grandiose ground support than in previous UAV missions at the SGP. The aircraft operation will include a more sophisticated sparing strategy to minimize downtime, as the Altus payload will include a complete set of spares for critical measurements. The payload will be preassembled and flight-tested before the mission, minimizing ground fixes. The Twin Otter will be used only as a chase plane.

Mini-MOPA (Master Oscillator Power Amplifier) Campaign (September 2000). The Mini-MOPA Campaign (Wynn Eberhard, NOAA Environmental Technology Laboratory [ETL]) was a potential participant in the DIAL/Raman Lidar Validation Intercomparison Campaign in the fall of 1999. However, the system did not return from the TWP in time to participate. The schedule of deployment is unknown at this time. This very compact DIAL system was used in the April 1996 SUCCESS Campaign at the SGP CART site in April 1996. The main goal of the Mini-MOPA Campaign is to demonstrate the performance and capabilities of the improved twowavelength DIAL measurements of water vapor. Alan Brewer (NOAA/ETL, abrewer@etl.noaa.gov) is the principal contact for this activity.

Fall SCM IOP (September 2000). This SCM IOP will occur in conjunction with the AFWEX experiment to improve characterization of upper tropospheric water vapor conditions. 
IHOP/TIMEx Campaign (Spring 2001). The National Severe Storms Laboratory's Thunderstorm Initiation Mobile Experiment (TIMEx) has been restructured into two parts: (1) investigation of upper tropospheric processes and (2) investigation of lower tropospheric/surface processes. The latter component has identified the need for mobile scanning devices to map the low-level moisture field. A pre-TIMEx initiative under a U.S. Weather Research Program grant, known as the International $\mathrm{H}_{2} \mathrm{O}$ Project (IHOP), would occur in spring 2001 and would attempt to involve all available water vapor measurement devices at the SGP CART site to investigate water vapor measurements for (1) thunderstorm initiation, (2) improvement of numerical weather prediction models, (3) improvement of data assimilation models, and (4) study of the relationship between water vapor and quantitative precipitation forecasting. Other goals would include instrument intercomparison and support of design studies for new DIAL systems. Among the measurement platforms desired are the National Center for Atmospheric Research Electra aircraft with DIALs and the mini-MOPA. As a result of a planning meeting held on April 1, 1999, IHOP was delayed from spring 2000 to spring 2001.

Spring SCM IOP (Spring 2001). This SCM IOP would support operations of the IHOP/TIMEx Campaign.

Aerosol IOP (Summer/Fall 2001). The Aerosol Working Group has proposed an Aerosol IOP during the dry season. 


\section{REFERENCES}

Dutton, E.G., J.J. Michalsky, T. Stoffel, B.W. Forgan, J. Hickey, D.W. Nelson, T.L. Alberta, and I. Reda, 2000, "Measurement of Broadband Diffuse Solar Irradiance Using Current Commercial Instrumentation with a Correction for Thermal Offset Errors," Journal of Atmospheric and Oceanic Technology (in press).

McPherson, R.A., and K.C. Crawford, 1996, "The EARTHSTORM Project: Encouraging the Use of Real-Time Data from the Oklahoma Mesonet in K-12 Classrooms," Bulletin of the American Meteorological Society 77:749-761.

Melvin, A.D., and R.A. McPherson, 1998, "Southern Great Plains Atmospheric Radiation Measurement (ARM) Educational Outreach Program," pp. 23-26 in Preprints, Seventh Symposium on Education, January 11-16, 1998, Phoenix, Arizona, American Meteorological Society, Boston.

Peppler, R.A., and M.E. Splitt, 1998, "ARM Southern Great Plains CART Site Data Quality Assessment Activities," pp. 355-358 in Preprints, Tenth Symposium on Meteorological Observations and Instrumentation, January 11-16, 1998, Phoenix, Arizona, American Meteorological Society, Boston.

Peppler, R.A., D.L. Sisterson, and P. Lamb, 1999, Site Scientific Mission Plan for the Southern Great Plains CART Site, January-June 1999, ARM-99-001, U.S. Department of Energy, Washington, D.C., January.

U.S. Department of Energy, 1990, Atmospheric Radiation Measurement Program Plan, DOE/ER-0441, Washington, D.C. (available online at http://www.arm.gov/docs/documents/ project/er_0441/toc.html).

U.S. Department of Energy, 1996, Science Plan for the Atmospheric Radiation Measurement Program (ARM), DOE/ER-0670T, Washington, D.C, February. 
